\title{
Раскатова E.M.
}

Раскатова Елена Михайловна - доктор исторических наук, профессор, Ивановский государственный химико-технологический университет, профессор кафедры истории и культурологии. E-mail: elenaraskatova@mail.ru

\section{ОФИЦИАЛЬНЫЕ ДОКУМЕНТЫ КАК ТЕКСТ КУЛЬТУРЫ: «ЛИЧНОЕ ДЕЛО» В. ЕРОФЕЕВА КАК ИНДИКАТОР ПОВЕДЕНЧЕСКИХ СТРАТЕГИЙ ВУЗОВСКОЙ ИНТЕЛЛИГЕНЦИИ НАЧАЛА 1960-х ГГ.}

\begin{abstract}
На материалах официальных документов («Личное дело» студента Владимирского государственного педагогического института В.В. Ерофеева будущего известного писателя) исследуются поведенческие стратегии вузовской интеллигенции периода «оттепели». Автор доказывает, что данный тематический документальный комплекс, представляет собой многослойный текст культуры, возникиий на пересечении различных идеологических и дискурсивных стратегий историко-культурного и общественнополитического контекстов.

Изучение контекста позволило обозначить факторы, определяющие историко-культурную ситуацию, - от оттепельных импульсов, попыток представить интеллектуальной молодежи учебный вариант неортодоксального марксизма и т.n., до ужесточения официальной политики, особенно заметно проявившееся в антирелигиозной кампании Н. С. Хрущева. Выявленные автором модели поведения демонстрируют неустойчивость позиций вузовской интеллигенции, ее зависимость от политических и идеологических схем, что стало благодатной почвой для сворачивания «оттепельных процессов» в ближайшем будущем.
\end{abstract}

Ключевые слова: текст культуры, тематический документальный комплекс, «Личное дело» студента Венедикта Ерофеева, оттепель, вузовская интеллигенция, антирелигиозная кампания Н.С.Хрущева.

\section{Raskatova E.M.}

Raskatova E.M. - Doctor of History, Professor, Ivanovo State University of Chemistry and Technology, E-mail: elenaraskatova@mail.ru

\section{OFFICIAL DOCUMENTS AS A CULTURAL TEXT: "PERSONAL FILE" OF V. EROFEEV AS AN INDICATOR OF BEHAVIORAL STRATEGIES OF THE UNIVERSITY INTELLIGENTSIA OF THE EARLY 1960s.}

On the materials of official documents ("Personal file" of a student of the Vladimir state pedagogical Institute V.V. Erofeev - a future famous writer), behavioural 
strategies of the University intelligentsia of the "thaw" period are studied. The author proves that this thematic documentary complex is a multi-layered text of culture that arose at the intersection of various ideological and discursive strategies of historical, cultural and socio-political contexts.

The study of the context allowed us to identify the factors that determine the historical and cultural situation: from thawing impulses, attempts to present an educational version of unorthodox Marxism to intellectual youth, etc., to the tightening of official policy, which was especially noticeable in the anti-religious campaign of N.S. Khrushchev. The behavior models identified by the author demonstrate the instability of the positions of the University intelligentsia, its dependence on political and ideological schemes, which has become a fertile ground for curtailing the "thaw processes" in the near future.

Key words: cultural text, thematic documentary complex, "Personal file" of student Venedikt Yerofeyev, thaw, University intelligentsia, anti- religious campaign of N.S. Khrushchev.

Современное гуманитарное знание все в большей степени стремится быть культурологическим, то есть, в качестве желаемого результата исследования, делать выводы о смыслах и ценностях культуры, выраженных в тех или иных культурных моделях, получающих конечную форму в соответствии с тем типом дискурса, в границах которого происходит их формирование. В этой, достаточно новой для российского контекста, научной парадигме особое значение получает понятие «текст культуры», представляющее собой своеобразное «эхо» фундаментального положения структурализма (в первую очередь, Р. Барта) о культуре как всеобъемлющем тексте, предлагающем «читателю» закодированную информацию [1]. В нашем случае, важно, что Барт настаивал на семантической открытости текста, на «неустранимой множественности» его смыслов, поскольку текст «бесконечно открыт в бесконечность», и никто «не в силах остановить движение текста». С этой точки зрения, каждый текст является интертекстом. Идею интертекстуальности развивает и Ю. Кристева, обращая внимание на присутствие в тексте текстов и окружающей, и предшествующей культур, на обязательности их диалога [8].

Российская (тартусско-московская) традиция семиотики в первую очередь, в лице Ю.М. Лотмана, в период своего расцвета, продуктивно продолжала и по-своему развивала, выстраивая параллельную картину, базовые идеи структурализма, уделяя внимание художественным текстам как носителям разнообразных культурных кодов, что выводило их из ряда однолинейных сообщений и сообщало таким текстам качества «самовозрастающего логоса», способного активно функционировать в различных культурных контекстах [11].

Таким образом, само понятие «текст культуры» приобрело сегодня ту многоплановость (при неизбежной размытости границ и включении в них не только художественных вербальных, но и визуальных и синтетических текстов; не только художественных, но и других возможных носителей «закодированной» культурной информации), которая и позволяет воспринимать его как «информационный генератор», способный привести нас «в общении с текстом» к пониманию разнообразных культурных полей, ставших его источником.

В нашем случае таким текстом являются официальные документы, которые выполняют сложные социально-коммуникативную функции (в соответствии с основными положениями концепции Ю.М. Лотмана):

- функцию сообщения, направленного от носителя информации к аудитории; 
- функцию коллективной культурной памяти, в качестве таковой он, с одной стороны, обнаруживает способность к непрерывному пополнению, а с другой, к актуализации одних аспектов вложенной в него информации и временному или полному забыванию других;

- функцию общения между текстом и культурным контекстом, когда текст воспринимается как заменитель всего контекста, которому он в определенном отношении эквивалентен.

Наконец, тексты (в том числе и тематические документальные комплексы) имеют тенденцию переходить из одного контекста в другой и, перемещаясь в другой культурный контекст, они "перекодируют самого себя" в соответствии с ситуацией обнажает аналогию между знаковым поведением личности и текста [11].

Официальные документы - это документы партийно-государственных и иных официальных структур советской политической системы (опубликованные и архивного хранения). Тематические документальные комплексы, как правило, связаны со значительными событиями художественной жизни, историями, имевшими заметный общественно-политический резонанс и ставшие в историческом контексте своеобразными маркерами изменений в культурной политике поздней советской эпохи (выпуск Литературно-художественного альманаха «МетрОполь», 1978-79 гг.; спектакль «Так победим!» по пьесе М. Шатрова МХАТ, 1981 г.; легендарный спектакль «Владимир Высоцкий» в Театре на Таганке, 1981 г. и многие другие). [15]

Полагаю, что и «Личное дело студента Венедикта Ерофеева», хранящееся в архиве Владимирского государственного педагогического института (университета) имени П.И. Лебедева-Полянского, предоставленное автору ректором Дмитрием Алексеевичем Макеевым [Прим. 1] в 2004 году, можно отнести к подобным документальным комплексам. «Личные дела», которые формировались как типовые в обязательном порядке на всех работавших в советских организациях, в некоторых неординарных/ чрезвычайных и т.п. ситуациях, дополнялись новыми документами (среди которых наиболее типичные объяснительные, служебные записки, справки, заявления, и др.), событие обрастало новыми подробностями и приобретало характер документальной культурной истории.

«Личное дело В. Ерофеева» [10] как текст культуры проявляет особенности контекста оттепельных 1960-х во всей их противоречивости; приближает к пониманию феномена вузовской культуры в СССР с ее идеологизацией научной и иной деятельности, особой ролью общественных структур (партия, комсомол и др.) в организации учебного процесса, всей студенческой жизни и др.; оно сохраняет и раскрывает особенности языка времени [Прим. 2].

Обращение исследователя к данным архивным документам с применением методики «кейс стадис» позволяет на материалах локальной культурной ситуации проявить важные черты времени, детализировать работу механизма власти при реализации культурной политики, определить поведенческие стратегии вузовской интеллигенции и студенчества в меняющихся условиях.

Папка документов «Личного дела» студента Ерофеева Венедикта Васильевича начата 21 мая 1961 г., закончена 31 января 1962 г.; документы на 20 листах, в том числе и оборотные страницы, включают: Заявление В.В. Ерофеева о приеме на заочное отделение, (ему почти 23 года, он уже имеет опыт учебы в вузе, работает на цементном заводе), автобиографию Венедикта Васильевича Ерофеева; экзаменационный лист с оценками «отлично» по всем предметам; текст сочинения «от руки» на тему «Личное и общественное в поэме Маяковского «Хорошо!»; приказ о зачислении на 1 курс очного отделения; выписка из Приказа об отчислении от 29 января 1962 г.; авторские документы, а именно: докладная декана филологического Засьмы Ларисы Лазаревны; 
справка, написанная преподавателем кафедры философии И.И. Дудкиным «от руки», синие чернила; письмо ректора Киктева Бориса Федоровича - на предприятие Начальнику УНР 646 тов. Уткину А.И. и др. [10]

Таким образом, нам стали известны хроника событий и главные /основные действующие лица этой истории, логику поступков которых постараемся прояснить.

Главное действующее лицо - Венедикт Васильевич Ерофеев, неординарный абитуриент, вскоре талантливый студент, будущий известный писатель, который, по мнению А. Зорина «открыл новый язык, новую реальность, нового героя и новый слой в словесности брежневской эпохи», почему и занимает особое место в истории российской литературы второй половины XX века [6, с. 256].

Уже во время вступительных экзаменов преподаватели педагогического института заметили и оценили уровень культуры, литературоведческую эрудицию и т.п. будущего студента. В первую очередь, это декан филологического факультета Лариса Лазаревна Засьма. По воспоминаниям самого В. Ерофеева, устный экзамен следовал после сочинения, уже проверенного и оцененного на «отлично». Позволим подробную цитату, раскрывающую и общую, в целом доброжелательную, атмосферу на экзамене, и готовность декана понять и принять особое (нерегламентированное) мнение уникального абитуриента по специальному вопросу, и предложение будущему студенту заняться научной работой и публиковаться в «Ученых записках» института.

«Июль 61-го. Город Владимир. Приемные испытания во Владимирский педагогический институт имени Лебедева-Полянского. Подхожу к столу и вытягиваю билет: 1. Синтаксические конструкции в прямой речи и связанная с ней пунктуация. 2. Критика 1860-х гг. о романе Н.Г. Чернышевского «Что делать?».

Трое за экзаменационным столом смотрят на меня с повышенным аппетитом. Декан филологического факультета Раиса Лазаревна с хроническою ульбкою: «Вам, судя по вашему сочинению о Маяковском, которое все мы расиенили по самому высшему баллу, — вам, наверное, и не надо готовиться к ответу. Присажсивайтесь.

А почему вы поступаете на заочное отделение? Вот мы все, и сидящие здесь, и некоторые отсутствуюшие, решили единогласно: вам место в стационаре, мы все убеждены, что экзамены у вас пройдут без единого "хор", об этом не беспокойтесь, да вы вроде и не беспокоитесь. 〈...> Мы обещаем вам самую почетную стипендию института, стипендию имени Лебедева-Полянского. Вы прирожденный филолог. Мы обеспечим вас научной работой. Вы сможете публиковаться в наших "Ученых записках" с тем, чтоб подкрепить себя материально...».

«Так будет ко мне хоть какой-нибудь пустячный вопрос, ну, хоть о литературных критиках 60-х г2.?» — «Будет. Так. Кто, по вамему разумению, оченил роман Николая Гавриловича самым точным образом?» - «По-моему, Аскоченский и чуть-чуть Скабичевский. Все остальные валяли дурака более или менее, от Афанасия Фета до Боткина». - «Позвольте, но как вам может нравиться мнение Аскоченского, злостного ретрограда тех времен?» Раиса Лазаревна: «О, на сегодня достаточно. Я, с согласия сидящего перед нами уникального абитуриента, считаю его зачисленным на дневное отделение под номером один, поскольку экзамены на дневное отделение еще не начались. Уже с 1 сентября мы должны становиться друзьями» [18, с. 152-154].

Что же случится за полгода учебы, что такое произойдет, что позволит /вынудит /заставит декана Л.Л. Засьму 27 января 1962 г.написать пространную докладную записку ректору с требованием об отчислении Венедикта Ерофеева?

«...Деканат, треугольник группы, профком, преподаватель-агитатор (Аксенова Е.М.) много занимались Ерофеевым, пытаясь помочь ему исправить его поведение. Его поведение дважды обсуждалось на собрании группы, в профкоме, на курсовом собрании. 
Я беседовала с ним подробно 4 раза, предлагала ему конкретную общественную работу. Однако все принятые меры не дали желательных результатов. Ерофеев ведет себя по-прежнему и самым отрицательным образом влияет на окружающих.

Считаю дальнейшее пребывание Ерофеева в институте невозможным. Прошу Вас принять соответствующие меры». [10, с. 7]

Отчисление студента первого курса, сдавшего все вступительные экзамены на «отлично» [10, с. 11], после первой сессии кажется странным, тем более, что первый экзамен он сдал на «отлично», а это было непросто при требовательности преподавателя Иорданского.[3, с. 165]

Автобиография В. Ерофеева [10, с. 13] позволяет говорить о типичности жизненного пути будущего студента педагогического института, а текст сочинения, проверенного и оцененное деканом на «отлично», на тему «Личное и общественное в поэме Маяковского «Хорошо!» демонстрирует видимую лояльность социалистическому образу мышления, с обязательным сюжетом про домыслы идеологических противников $[10$, с. 18-20, 20 об.]. Более того, из подробной биографии, представленной Е.Н. Шталем, следует, что «Ерофеев с первых же дней окунулся в учебу. Он написал несколько статей для "Ученых записок Владимирского пединститута" о творчестве норвежских писателей. О Генрике Ибсене, Бьернсоне, Кнуте Гамсуне...». Однако, напоминает автор: «все они были отвергнуты на том основании, что «методологически никуда не годятся» [4, с. 253; 19].

Первый звонок о неблагополучии...

К докладной записке декана приложена «справка», составленная преподавателем кафедры философии Дудкиным Игорем Ивановичем и которая многое помогает объяснить в действиях руководителя факультета. Считаем необходимым подробное цитирование:

«Мне пришлось случайно беседовать со студентом 1 курса т. Ерофеевым.

Разговор шел на философские темы. Формальным поводом для беседы был вопрос о возможности его участия в философском кружке. Надо заметить, что с самого начала Ерофеев отбросил (неразборчиво - E.P.) все претензии диалектического материализма на возможность познания истины. Он заявил, что истина якобы не одна. И на мои доводы он ответил не более, как усмешкой.

В разговоре он показал полную политическую и методологическую незрелость, он бездоказательно отвергает коренные принципиальные положения марксизма: основной вопрос философии, (неразборчиво) философии и т.д. Более того, его хвастливопетушиный и весьма неприличный тон очень неприятно действовал на окружающих. $<\ldots>$

Я, как преподаватель философии считаю, что Ерофеев не может быть в числе наших студентов по следующим причинам.

1. Он самым вреднейшим образом воздействует на окружающих, пытаясь посеять неверие в правоту нашего мировоззрения.

2. Мне представляется, что он не просто заблуждается. А действует, как вполне убежденный человек, чего, впрочем, он и сам не скрывает» $[10$, с. 4].

С чем связано создание этого текста? 1962 год... Оттепель... Еще не наступили «заморозки». Уже был ХХ съезд КПСС, послуживший началом десталинизации и некоторого раскрепощения общественного сознания, в том числе и вузовской интеллигенции. Началась реабилитация, и в российской культуре восстановлены многие имена, появилась новая литература и др. Еще не опубликован, но уже читается и готовится к печати «Один день Ивана Денисовича» А. Солженицына. Появилась, правда, еще редкая возможность читать в «спецхранах» библиотек редкие книги отечественных и зарубежных авторов. Пушкинский музей в 1955 году провел выставку из собраний Дрез- 
денской галереи. В 1956 году в столице была организована выставка работ Пабло Пикассо. Во время Фестиваля молодежи (1957) в Москве, в Сокольниках можно было увидеть работы современных американских художников и т.д. и т.п.

Казалось бы, еще не было разгрома художников-авангардистов в Манеже (01 декабря 1962 г.), встреч Н.С. Хрущева с интеллигенцией (декабрь 1962, март 1963) и других признаков сворачивания демократических процессов в советском обществе.

Конечно, общественная атмосфера провинции качественно отличалась от столичной и по-прежнему оставалась достаточно консервативной.

Каковы мотивы поступка еще одного и, видимо, ключевого, участника культурной истории? Искреннее стремление защитить марксизм-ленинизм от необоснованных нападок? Неспособность вести серьезную дискуссию и потому желание избавиться от ненужного оппонента и тем самым сохранить влияние на студентов? Партийная дисциплина, требующая «информировать» соответствующие органы обо всех случаях отклоняющегося поведения учащихся? Или страх за себя, свое рабочее место, которого можно лишиться, если вовремя не «сигнализировать» об идеологическом неблагополучии в профессорско-преподавательской и студенческой среде института? В предлагаемых временем обстоятельствах каждый человек ведет себя по-своему, в соответствии с собственными представлениями о гражданском долге, нравственности и профессионализме.

Сегодня показанная модель поведения кажется странной. По данным Е.Н. Шталя, из воспоминаний современников и др. источников, Игорь Дудкин не преподавал на первом курсе философию, но вел беседы в неформальной обстановке с умным нестандартно мыслящим студентом/студентами. Что это? Нарождающийся в среде интеллигенции цинизм, отражавший двойную мораль? Или он был информатором и сознательно провоцировал подобные разговоры? Может быть, это была наивность человека, уверенного, что «все обойдется», студента 1 курса не накажут. Но как бы то ни было, текст «Справки» - образец «доносов» того времени по разного рода идеологическим поводам.

Не реагировать на такое содержание «справки» декан филологического факультета не могла, тем более что предпринятые ею меры по воспитательному воздействию на В.В. Ерофеева результата не дали. Более того, она прекрасно понимала, что оригинально мыслящий, нестандартно ведущий себя студент становится неформальным лидером факультета, за который она отвечает и которым становится все сложнее управлять.

Из «Записных книжек» самого писателя следует, что прежде чем отчислить, с ним беседовал и сам ректор Борис Федорович Киктёв [Прим. 3.]. Он понимал и также ценил студента Венедикта Ерофеева, одаренного, с особым видением мира, даже неосторожным образом жизни (вино, влюбленности, опасное чтение и т.п.), сетовал на сложившуюся ситуацию ... Его письмо Начальнику предприятия УНР 646 товарищу А.И. Уткину с просьбой принять В.В. Ерофеева на работу, обязательно предоставить жилье отчисленному студенту, свидетельствует о его заинтересованном участии в судьбе талантливого человека, что подтвердил автору и профессор Д.А. Макеев. Полагаем, что возглавив вуз в новых условиях оттепели, Б.Ф. Киктев оставался человеком оттепели. Именно поэтому он мог позволить и идеологическую новацию - введение в учебные планы новой общественной дисциплины «научный коммунизм» расценить как возможность представления интеллектуальной молодежи учебного варианта неортодоксального марксизма, что могло помочь в коммунистическом воспитании студентов, тем более будущих педагогов. По мнению специалистов, ученых-гуманитариев, создававших и отстаивающих «научный коммунизм» в границах модернизации идеологии периода оттепели, тема нового человека нового коммунистического общества это, прежде всего, тема гуманизма, ценности человеческой личности в обществе, где «свободное развитие каждого является условием свободного развития всех» (К. Маркс). 
[13, с. 447; Прим. 4]. Поэтому мыслящий и дискутирующий по мировозренческим вопросам студент должен становится поведенческой нормой.

Но что же заставило руководителей вуза, знавших и высоко ценивших талант начинающего филолога, в сложившейся ситуации принять такие жесткие меры? Позволим предположить внешние для вуза обстоятельства - резкое изменение идеологических векторов, а именно - антирелигиозная кампания Н.С. Хрущева, начавшаяся еще после XX съезда КПСС (1956) и усилившаяся после XXII съезда КПСС (1961). Специалисты обращают внимание на два документа, определивших действия власти: 13 января 1960 года выходит постановление ЦК «О мерах по ликвидации нарушений духовенством советского законодательства о культах», через год выходит постановление «Об усилении контроля за деятельностью Церкви» (1961 г.) [15]. Современные исследователи этой проблемы обращают внимание на чрезвычайные методы проведения атеистической работы. [5, 7, 17 и др.]

Программа построения коммунистического общества предполагала, что современная молодёжь будет жить в условиях, где нет места религии. Поэтому особое внимание уделялось атеистическому воспитанию молодежи. «Религия — яд!» - утверждали официальные плакаты и пропагандисты, а студент филологического факультета В. Ерофеев занимается, как следует из служебной записки, «чтением и распространением среди студентов Библии (в тексте была маленькая буква, потом исправлена на большую - E.P.), привезенной им в общежитие, якобы, «для изучения источников средневековой литературы» [10, с. 1].

Сам В.В. Ерофеев об этом писал следующее: «Тихонечко держал у себя в тумбочке Библию. Для меня эта книга есть то, без чего невозможно жить. Я из нее вытянул все, что можно вытянуть человеческой душе, и не жалею об этом. А тех, кто с ней не знаком, считаю чрезвычайно несчастным и обделенным. Библию я знаю наизусть и могу этим похвалиться. Спустя какое-то время книгу в моей тумбочке обнаружили, и началось такое!.. Я помню громадное всеобщее собрание института, ужас преподавателей и студентов. Мне этот ужас был непонятен...» [4, с. 269-270; 19].

В педагогическом институте Ерофеев участвовал в литературных кружках, сообщает Е.Н. Штальа затем создал и свой кружок, где читал друзьям лекции по истории христианства, знакомил их с идеями Николая Бердяева и Василия Розанова. Кружок действовал подпольно. Ерофеева неоднократно вызывали «на ковер» к ректору, но все было тщетно [19]. Было по какому поводу беспокоиться руководителям. «Ерофеев оказывает самое отрицательное влияние на ряд студентов 1-го и старших курсов, декан Л.Л. Засьма перечисляет фамилии, в том числе, Валентину Зиманову, (любовь и будущую жену), благодаря систематическим разговорам на «религиозно-философские» (так он называет) темы» $[10$, с. 1 (об.)].

Вряд ли умному студенту В.В. Ерофееву был совсем непонятен «этот ужас». В «Записных книжках» есть его симптоматичное замечание «C 30 авг. 1961 г. - начало непреднамеренного и тихого разложения Владимирского пединститута» [3, с. 159].

30 января 1962 года ректор подписал приказ об отчислении «студента 1 курса Ерофеева Венедикта Васильевича как не сдавшего зачетную сессию по неуважительным причинам и не явившегося по неуважительной причине на экзамен по «устному народному творчеству», а также как человека, моральный облик которого не соответствует требованиям, предъявляемым уставом ВУЗа и будущему учителю и воспитателю молодого поколения, исключить из состава студентов филологического факультета института» $[10$, с. 3$]$.

За исключением студента Венедикта Ерофеева последовали череда мер: отчисление студентов, связанных с ним дружеским и интеллектуальным общением; от некоторых требовали отречения в буквальном смысле - предлагали выбор «или Ерофеев / 
или институт». Особенно тяжело переживала ситуацию В. Зиманова, студентка старшего курса, которую связывали с Ерофеевым личные отношения [19].

Так руководители Владимирского педагогического института - советского государственного вуза выполняли указания власти, следовали официальной идеологии, реализовывали меры по атеистическому воспитанию и искоренению религиозных пережитков в молодежной среде.

Это был опыт и для студента Венедикта Ерофеева. Опыт, разрушивший миф о гармонии личного и общественного, который был едва ли не важнейшим для поколения 1960-х. Абитуриент Ерофеев писал об этом во вступительном сочинении «Личное и общественное в поэме Маяковского «Хорошо!»: «Следует отметить, что Маяковский, поэт советской эпохи, вносит новое в поэтическое понимание связи личного и общественного. Для Некрасова и Пушкина, например, единство их интересов с интересами народа необходимо предполагало ненависть $\kappa$ существующему режиму и кложной «официальной идеологии». Маяковский, напротив, не отделяет «общественное» от «государственного», «государственное»от «личного». Интересы и воля его народа находят лучшее выражение в политике его власти, его /П/партии (большая буква зачеркнута - E.P.), той партии, которая «направляла, строила в ряды» движение народных масс и чье мудрое руководство револючией на всех ее фронтах, дает поэту право быть уверенным в могуществе того отечества, «которое будет» [10, с. 20, 20 (об.)].

Можно предположить сознательную лояльность умного взрослого человека... Однако обращение к «Записным книжкам» 1960, 1961 годов позволяет думать, что автор много и серьезно размышлял о предназначении человека, о его возможностях и способах служения обществу, о гражданственности и ответственности писателя, философа, образованного интеллектуала в России. Предметом его исследовательского интереса были дневники и письма А.И. Герцена, П.Я. Чаадаева, Ф.М. Достоевского и др. $[3,151,153,154$ и др.]. Его обращение к творчеству В. Маяковского - продолжение поиска ответа на вопрос: можно ли личное встроить в общественное. Если согласиться с утверждением о культурно-исторических параллелях 1920-х и 1960-х годов, то предположим, что Ерофеев как человек эпохи (оттепельный импульс) и как молодой человек-романтик искал подтверждения своим представлениям в текстах революционного поэта.

В «Записных книжках» 1962 года почти нет выписок из текстов, цитатразмышлений. Они возобновятся только в 1963 году. В. Ерофеев будет изучать Шеллинга и Монтескье, Ортега-и-Гассета, Хайдеггера и многих других. Он будет искать выход... Своеобразное молчание 1962 года, зафиксированное в «Записных книжках», свидетельствует о степени потрясения случившимся. Вино помогало забыть, но не спасало и не предлагало выхода. Потрясение было велико, т.к. при всей трезвости и реалистичности в оценках происходящего В. Ерофеев не мог смириться с «абсурдом случившегося». Он принадлежал к поколению, взрослевшему в оттепель, не знавшему тотального страха.

Документальная история студента Владимирского государственного педагогического института Венедикта Ерофеева на этом обрывается.

Творческая биография всемирно известного писателя только начиналась. Современное литературоведение утверждает, что повесть «Москва-Петушки» отражает религиозно-философские и нравственные искания целого поколения, трагедию невостребованности интеллектуала и становится неким символом времени - начинавшейся эпохи «застоя» [2, 9, 19 и др.; Прим. 5]

Проведенное исследование «Личного дела студента В. Ерофеева» позволяет говорить о том, что этот документальный комплекс, имеющий, на первый взгляд, локаль- 
ное историческое значение, представляет собой многослойный текст культуры, возникший на пересечении различных идеологических и дискурсивных стратегий историко-культурного и общественно-политического контекстов.

Кроме того, что конкретные документы дают возможность уточнить и детализировать ситуацию (причины, механизм) отчисления В. Ерофеева из Владимирского государственного педагогического института, ее реконструкция углубляет понимание специфики культурной ситуации начала 1960-х годов как ситуации, подготавливающей исторический перелом - переход с позиций «оттепели» на позиции жесткого государственного контроля за развитием социально-гуманитарной сферы.

Противоречивость «позднеоттепельных» процессов выражена, с нашей точки зрения, в поведенческих моделях вузовской интеллигенции, в первую очередь, научнопедагогической, для которой, в какой-то момент является важным проявление свободы и гуманизма, положительное внимание к новым, нестандартным формам гуманитарного мышления (которые демонстрирует абитуриент и студент В. Ерофеев), но эта же интеллигенция готова в другой момент, под давлением внешних обстоятельств или «внутреннего цензора», выбрать консервативную модель поведения, показывающую ее лояльность жесткому курсу официальной политики (в данном случае - антирелигиозной кампании Н.С. Хрущева).

Противоречивость сознания культурного человека поздней советской эпохи проявила себя в различных формах общественно-значимых культурных реакций — от ортодоксальной, но, очевидно, искренней линии поведения, не допускающей идеологических демаршей, до не явно читаемой «двойной морали», провоцирующей «идейные отклонения» с целью доносительства; была возможна и третья линия - попытка проявить гуманизм в пределах, допустимых жесткими нормами. Но, так или иначе - все эти стратегии демонстрируют неустойчивость позиций вузовской интеллигенции, ее зависимость от политических и идеологических схем, что, конечно, стало благодатной почвой для сворачивания «оттепельных процессов» в ближайшем будущем.

Ситуация, сложившаяся вокруг отчисления В. Ерофеева, стала своеобразным «эхом» проблемы, поднятой им в сочинении, написанном на вступительном экзамене («Личное и общественное в творчестве Маяковского»). Можно сказать, что «личное» и «общественное» вступили в этой истории в драматическое противоречие, и «общественное», в данном случае, оказалось более сильным механизмом, определившим исход конфликта.

Текст культуры, как уже было отмечено, в силу своей природы имеет диалогический характер и это - не только диалог с тем контекстом, который вызвал его к жизни, но и с сегодняшним днем также. Вузовская среда и сегодня - медиатор общественноисторических процессов, а, возможно, и их катализатор. Изучение поведенческих стратегий вузовской интеллигенции постсталинского периода позволяет нам глубоко и всесторонне осмысливать черты той культурной модели, которая во многом определяет параметры развития общества, как в настоящем, так, возможно, и в будущем.

\section{СПИСОК ЛИТЕРАТУРЫ}

1. Барт Р. Избранные работы Семиотика. Поэтика. М.: Прогресс, 1989. С. 413-423.

2. Власов Э. Москва-Петушки. Спутник писателя. Sapporo, 1998.

3. Ерофеев В. Записные книжки 1960-х годов. Первая публикация полного текста. М: Захаров, 2005. $672 \mathrm{c}$

4. Ерофеев В.В. Собр. соч.: В 2 томах. М.: Вагриус, 2001. Т. 2. 382 с.

5. Зинчук С.М. Хрущевская антирелигиозная кампания в 1954-1964 гг.: практическая реализация и результаты // Вестник Костромского гос. ун-та, 2019. № 1. С. 71-75.

6. Зорин А. Пригородный поезд дальнего следования // Новый мир, 1989. № 5. С. 256-258. 
7. Иошкин М.В. Влияние религии и атеизма на молодежь в 1958-1964 гг. (на материалах Тамбовской области): автореф. дис. ... канд. ист. наук. Тамбов, 2015. 24 с.

8. Кристева Ю. Семиотика: Исследования по семанализу. М.: Академический проект, 2013. $285 \mathrm{c}$.

9. Лекманов О.А., Свердлов М.И., Симановский И.Г. Венедикт Ерофеев: посторонний. М.: ACT, 2018. $464 \mathrm{c}$.

10. «Личное дело» студента ВГПИ Венедикта Ерофеева // Архив ВГПУ. Владимирский государственный педагогический институт им. П.И. Лебедева-Полянского. Опись 1454. Д. Я-11. Начато 1 сентября 1961 г. Окончено 30 января 1962 года. (на 20 листах).

11. Лотман Ю.М. Семиотика культуры и понятие текста. Избранные статьи. Таллинн, 1992. T. 1. C. 129-132.

12. Малиновский В.В. Становление и развитие системы высшего образования в Алтайском крае в 30-80-е годы XX в.: дис. ... канд. ист. наук. Барнаул, 2019. С. 95-96.

13. Маркс К., Энгельс Ф. Манифест Коммунистической партии. Раздел Пролетарии и коммунисты. 1955. Т. 4. С. 447.

14. О религии и церкви: сборник документов. М.: Изд-во политической литературы, 1965. $128 \mathrm{c}$.

15. Раскатова Е.М. Власть и художественная интеллигенция: логика конфликта. Иваново: Издательство Ивановского гос. ун-та, 2009. 326 с.

16. Раскатова Е.М. Советская высшая школа и официальная идеология: к истории «Личного дела» Венедикта Ерофеева // Социум: проблемы, анализ, интерпретации: сб. науч. тр. Вып. IV. М.: МПГУ, 2005. С. 165-168.

17. Чумаченко Т.А. Государство и Русская православная церковь в 1958-1964гг.: новая политическая война с религией, церковью и верующими // Вестн. Челябинского гос. ун-та. Сер.: Право. 2014. Вып. 39. № 19 (348). С. 82-90.

18. Шмелькова Н.А. Последние дни Венедикта Ерофеева: Дневники. М.: Вагриус, 2002. $320 \mathrm{c}$.

19. Шталь Е.Н. Венедикт Ерофеев: писатель и его окружение. М: АИРО-ХХІ, 2019. 240 с.

\section{REFERENCES (TRANSLITERATED)}

1. Bart R. Izbrannyye raboty Semiotika. Poetika. M.: Progress, 1989. S. 413-423.

2. Vlasov E. Moskva-Petushki. Sputnik pisatelya. Sapporo, 1998.

3. Yerofeyev V. Zapisnyye knizhki 1960-kh godov. Pervaya publikatsiya polnogo teksta. M: Zakharov, 2005. $672 \mathrm{~s}$.

4. Yerofeyev V.V. Sobr. soch.: V 2 tt. M.: Vagrius, 2001. T. 2. $382 \mathrm{s.}$

5. Zinchuk S.M. Khrushchevskaya antireligioznaya kampaniya v 1954-1964 gg.: prakticheskaya realizatsiya i rezul'taty // Vestnik Kostromskogo gos. un-ta, 2019. № 1. S. 71-75.

6. Zorin A. Prigorodnyy poyezd dal'nego sledovaniya // Novyy mir, 1989. № 5. S. 256-258.

7. Ioshkin M.V. Vliyaniye religii i ateizma na molodezh' v 1958 - 1964 gg. (na materialakh Tambovskoy oblasti): avtoref. dis. ... kand. ist. nauk. Tambov, 2015. $24 \mathrm{~s}$.

8. Kristeva YU. Semiotika: Issledovaniya po semanalizu. M.: Akademicheskiy proyekt, 2013. $285 \mathrm{~s}$.

9. Lekmanov O.A., Sverdlov M.I., Simanovskiy I.G. Venedikt Yerofeyev: postoronniy. M.: AST, 2018. $464 \mathrm{~s}$.

10. «Lichnoye delo» studenta VGPI Venedikta Yerofeyeva // Arkhiv VGPU. Vladimirskiy gosudarstvennyy pedagogicheskiy institut im. P.I. Lebedeva-Polyanskogo. Opis' 1454. D. YA11. Nachato 1 sentyabrya 1961 g. Okoncheno 30 yanvarya 1962 goda. (na 20 listakh).

11. Lotman Yu.M. Semiotika kul'tury i ponyatiye teksta. Izbrannyye stat'i. Tallinn, 1992. T. 1. S. 129-132.

12. Malinovskiy V.V. Stanovleniye i razvitiye sistemy vysshego obrazovaniya v Altayskom kraye v 30-80-ye gody KHKH v.: dis. ... kand. ist. nauk. Barnaul, 2019. S. 95-96.

13. Marks K., Engel's F. Manifest Kommunisticheskoy partii. Razdel Proletarii i kommunisty. 1955. T. 4. S. 447.

14. O religii i tserkvi: sbornik dokumentov. M.: Izd-vo politicheskoy literatury, 1965. $128 \mathrm{~s}$. 
15. Raskatova Ye.M. Vlast' i khudozhestvennaya intelligentsiya: logika konflikta. Ivanovo: Izdatel'stvo Ivanovskogo gos. un-ta. 2009. $326 \mathrm{~s}$.

16. Raskatova Ye.M. Sovetskaya vysshaya shkola i ofitsial'naya ideologiya: k istorii «Lichnogo dela» Venedikta Yerofeyeva // Sotsium: problemy, analiz, interpretatsii: sb. nauch. tr. Vyp. IV. M.: MPGU, 2005. S. 165-168.

17. Chumachenko T.A. Gosudarstvo i Russkaya pravoslavnaya tserkov' v 1958-1964gg.: novaya politicheskaya voyna s religiyey, tserkov'yu i veruyushchimi // Vestn. Chelyabinskogo gos. un-ta. Ser.: Pravo. 2014. Vyp. 39. № 19 (348). S. 82-90.

18. Shmel'kova N.A. Posledniye dni Venedikta Yerofeyeva: Dnevniki. M.: Vagrius, $2002.320 \mathrm{~s}$

19. Shtal' Ye.N. Venedikt Yerofeyev: pisatel' i yego okruzheniye. M: AIRO-XXI, 2019. 240 s.

\section{ПРИМЕЧАНИЯ}

1. Макеев Дмитрий Алексеевич, доктор исторических наук, профессор - ректор ВГПУ в 1988 -2007 гг., передавая документы автору, напомнил о некоторых этических нормах при использовании имен действующих лиц при публикации, что и было исполнено в первой научной работе по этому сюжету [16]. В появившихся позднее в сети материалах были обозначены «поименно» все герои.

2. Например, термин ««преподаватель-агитатор», объяснение которому автор обнаружил только в тексте диссертации В.В. Малиновского: «В иелях политико-воспитательной и культурно-массовой работы, помимо ставщих регулярными политинформаций, $\kappa$ каждой группе был прикреплен преподаватель-агитатор, который направлял всю воспитательную работу в группе» [12, с. 95-96 ].

3. Киктёв Борис Федорович, профессор — ректор ВГПИ в 1960-1984 гг. Принял вуз в эпоху оттепели, способствовал его развитию, организации новых кафедр, при нем вуз занял достойное место среди педагогических институтов. В 1977 г. вуз награжден переходящим Красным знаменем Совета министров РСФСР и ВЦСПС за успехи, достигнутые в подготовке педагогических кадров.

4. Формальной точкой отсчета появления научного коммунизма считается 30 января 1962 года, когда на Всесоюзном совещании заведующих кафедр общественных наук выступил секретарь ЦК КПСС М.А. Суслов // https://lenta.ru/articles/2015/08/08/ sciencecommunism/ (дата обращения: 23 01.2020).

5. Современная библиография научных трудов, посвященных творчеству В.В. Ерофеева, занимает несколько страниц, среди исследователей Н.А. Богомолов, Ю.Б. Орлицкий, М.Н. Липовецкий, М.Н. Эпштейн, Е.М. Тюленева, Е.Е. Смирнова и мн. др.; в 2018 г. появилась принципиально важная работа Лекманова О.А., Свердлова М.И., Симановского И.Г. [10]; в 2019 г. итоги своей многолетней разыскательской деятельности подвел Е.Н. Шталь [19] и т.д.

Поступила в редакцию 28.02.2020 г. Принята к публикации 10.03.2020 г.

Для циитирования:

Раскатова Е.М. Официальные документы как текст культуры: «Личное дело» В. Ерофеева как индикатор поведенческих стратегий вузовской интеллигенции начала 1960х гг. // Вестник Гуманитарного института. 2020. № 1. C. 30-40. URL: https://isuctbhi.ru/sites/default/files/issue/2020/1/bhi-2020-1-030.pdf 